\title{
Identification and bioactive potential of endophytic fungi isolated from selected plants of the Western Himalayas
}

Masroor Qadri ${ }^{1}$, Sarojini Johri ${ }^{1}$, Bhahwal A Shah², Anamika Khajuria ${ }^{3}$, Tabasum Sidiq ${ }^{3}$, Surrinder K Lattoo ${ }^{4}$, Malik Z Abdin ${ }^{5}$ and Syed Riyaz-Ul-Hassan ${ }^{1 *}$

\begin{abstract}
This study was conducted to characterize and explore the endophytic fungi of selected plants from the Western Himalayas for their bioactive potential. A total of 72 strains of endophytic fungi were isolated and characterized morphologically as well as on the basis of ITS1-5.8S-ITS2 ribosomal gene sequence acquisition and analyses. The fungi represented 27 genera of which two belonged to Basidiomycota, each representing a single isolate, while the rest of the isolates comprised of Ascomycetous fungi. Among the isolated strains, ten isolates could not be assigned to a genus as they displayed a maximum sequence similarity of 95\% or less with taxonomically characterized organisms. Among the host plants, the conifers, Cedrus deodara, Pinus roxburgii and Abies pindrow harbored the most diverse fungi, belonging to 13 different genera, which represented almost half of the total genera isolated. Several extracts prepared from the fermented broth of these fungi demonstrated strong bioactivity against E. coli and S. aureus with the lowest $\mathrm{IC}_{50}$ of $18 \mu \mathrm{g} / \mathrm{ml}$ obtained with the extract of Trichophaea abundans inhabiting Pinus sp. In comparison, extracts from only three endophytes were significantly inhibitory to Candida albicans, an important fungal pathogen. Further, 24 endophytes inhibited three or more phytopathogens by at least $50 \%$ in co-culture, among a panel of seven test organisms. Extracts from 17 fungi possessed immuno-modulatory activities with five of them showing significant immune suppression as demonstrated by the in vitro lymphocyte proliferation assay. This study is an important step towards tapping the endophytic fungal diversity from the Western Himalayas and assessing their bioactive potential. Further studies on the selected endophytes may lead to the isolation of novel natural products for use in medicine, industry and agriculture.
\end{abstract}

Keywords: Endophytes, Western Himalayas, Fungal diversity, Conifers, Antimicrobial activity, Immuno-modulation, ITS

\section{Introduction}

Microorganisms are important sources of bioactive natural products with enormous potential for the discovery of new molecules for drug discovery, industrial use and agricultural applications (Demain 1999; Keller et al. 2005; Strobel 2006; Porras-Alfaro and Bayman 2011). Natural products remain a consistent source of drug leads with more than $40 \%$ of new chemical entities (NCEs) reported from 1981 to 2005 having been derived from microorganisms (Khosla 1997; Clardy and Walsh

\footnotetext{
* Correspondence: srhassan@iiim.ac.in

${ }^{1}$ Microbial Biotechnology Division, CSIR-Indian Institute of Integrative Medicine, Canal Road, Jammu 180001, India

Full list of author information is available at the end of the article
}

2004; Sieber and Marahiel 2005). Further, more than $60 \%$ of the anticancer and $70 \%$ of the antimicrobial drugs currently in clinical use are natural products or natural product derivatives (McAlpine et al. 2005). This is not surprising in the light of their evolution over millions of years in diverse ecological niches and natural habitats. In comparison to other natural sources like plants, microorganisms are highly diverse but narrowly explored. Studies based on estimation of microbial populations have revealed that only about $1 \%$ of bacteria and $5 \%$ of fungi have been characterized and the rest remain unexplored for their contribution to the human welfare (Heywood 1995; Staley et al. 1997).

\section{望}


The potential of microorganisms is further limited by the presence of orphan biosynthetic pathways that remain unexpressed under general laboratory conditions (Bok et al. 2006; Hertweck 2009). However, the vast choice of techniques pertaining to the growth and manipulation of microorganisms like media engineering, co-culture, chemical induction, epigenetic modulation and metabolite remodeling, coupled with the fermentation technology for scale up, make them suitable for production of useful natural products, both known and novel (Bok et al. 2006; Bergmann et al. 2007; Knappe et al. 2008; Schroeckh et al. 2009; Riyaz-Ul-Hassan et al. 2012). Thus, it has become imperative to explore microorganisms for NCEs and leaddrug-molecules to run sustainable programs like drug discovery. Consequently, bioprospecting of microorganisms is carried out from every possible source, including extreme environments like ocean beds, geothermal vents, cold desserts etc., in search of novel strains with promising bioactivities (Staley et al. 1997; Selvin et al. 2010; Paul Antony et al. 2012).

During the last 20 years, it has been observed that much of the wealth of microbial biodiversity with novel biochemistry and secondary metabolite production resides in plant tissues (Strobel 2006; Porras-Alfaro and Bayman 2011). Interest in such microorganisms, termed as endophytes, increased immensely with the discovery of an endophytic fungus, from Taxus brevifolia, producing the billion dollar anti-cancer drug, taxol (Stierle et al. 1993). Numerous bioactive molecules have been isolated from endophytic fungi since this ground breaking discovery (Strobel 2006; Wang et al. 2011; Zhang et al. 2012). Endophytes are metabolically more active than their free counterparts due to their specific functions in nature and activation of various metabolic pathways to survive in the host tissues (Strobel and Daisy 2003; Strobel 2006; Riyaz-Ul-Hassan et al. 2012). As the previous research on endophytes mainly focused on search for the host-plant metabolites in the endophytic partner (Stierle et al. 1993; Puri et al. 2006; Kusari et al. 2009), the theory of horizontal transfer from the host plant to its microbial symbiont received much impetus (Strobel 2006). However, the sequencing of the taxadiene synthase gene from the taxol-producing endophyte revealed that endophytes possess biosynthetic pathways independent of the plant host (Staniek et al. 2009). This indicates that microorganisms have much more biosynthetic proficiency than previously thought. Thus, microorganisms may be screened for a wide range of biological activities and explored for useful chemical entities consistently produced by them.

Establishment of microbial repositories from various ecological niches is an important step towards tapping their potential for human welfare, including drug discovery and sustainable agriculture. The Himalayas and its foothills represent an important biodiversity hot-spot of the world (Hanson et al. 2009). The state of Jammu and Kashmir (J\&K) possesses a significant portion of Himalayas (Western Himalayas), with areas of high altitude, cold desserts, glaciers and immense plant diversity including a plethora of medicinal and aromatic plants (Khuroo et al. 2007; Hanson et al. 2009). The microbial resources of the Western Himalayas, particularly the endophytic populations, are mostly unexplored. Thus, an investigation was carried out to isolate and characterize the endophytic fungi of selected plants growing in the Himalayas and its foothills, with the aim to establish a repository, explore their bioactive potential and isolate new leads for drug discovery, industry and agriculture. In this report, we describe the characterization of endophytic fungi obtained from such plants and their bioactive potential with respect to antimicrobial activity and immune modulation.

\section{Materials and Methods Collection of the host plants}

Small cuttings (about $10 \mathrm{~cm}$ ) of the stems or twigs of the plants were collected from specific locations in the Western Himalayas of the Lolab Valley (6000-6500 feet; $\left.34^{\circ} 31^{\prime} 13^{\prime \prime N}, 74^{\circ} 22^{\prime} 55^{\prime \prime E}\right)$ and Sadhana Top (11,000 feet; $\left.34^{\circ} 24^{\prime} 5^{\prime \prime} \mathrm{N}, 73^{\circ} 57^{\prime} 14^{\prime \prime} \mathrm{E}\right)$. Lolab valley is known for its dense Cedrus forests whereas Sadhna top is thickly covered with wild growing Artemisia and Mentha species in addition to dense coniferous trees and other medicinal plants. Multiple numbers of samples from individual trees ( $\mathrm{n}=20$ for each) of Cedrus deodara and Pinus roxburgii were collected from both the locations. Samples of Platanus orientalis and Cannabis sativa were collected from the former location whereas Abies pindrow, and Artemisia annua were obtained from the latter. Shoot cuttings of Picrorhiza kurroa were procured from the Himalayan region of Sonamarg $\left(34^{\circ} 18^{\prime} 17^{\prime \prime} \mathrm{N}, 75^{\circ}\right.$ $17^{\prime} 8^{\prime \prime}$ E). Specimens of other plants, Withania somnifera, Rauwolfia serpentina and Nothapodytes nimmoniana were collected from the foothills of Shivalik range of Himalayas at Jammu (32 $\left.43^{\prime} 54^{\prime \prime} \mathrm{N}, 74^{\circ} 50^{\prime} 53^{\prime \prime} \mathrm{E}\right)$. For each host, samples from ten plants were collected except for Nothapodytes nimmoniana, wherein samples were collected from a single plant. The plant materials were transported to the lab in sterile polythene bags and stored at $4^{\circ} \mathrm{C}$ until processed. The authenticated specimen of the collection were deposited in the CSIR-IIIM herbarium, Jammu, India (Table 1).

\section{Isolation of endophytes}

Endophytic fungi were isolated as described previously by Ezra et al. (2004). Plant materials were thoroughly washed with running tap water, cut under sterile conditions into small pieces $(2-3 \mathrm{~cm})$ and surface sterilized with $1 \%$ sodium hypochlorite and $90 \%$ ethanol, respectively. Before 
Table 1 The list of endophytes isolated in this study, their host plants and the summary of BLAST results, showing the coverage of the sequences and sequence similarities with the most closely related organisms (Altschul et al. 1997)

No. Plant host; Voucher no. $\quad$ Endophytes isolated (GenBank Acc. no. of the ITS sequence)

Query

\section{\% sequence} similarity

Picrorhiza kurroa; RRL(H)17772

PR1 ( JQ769230)

PR2 ( JQ769231)

PR3 ( JQ769232)

PR4 ( JQ769233)

2. Cannabis sativa; RRL(H)18255

CN1 ( JQ769234)

CN2 ( JQ769235)

CN3 ( JQ769236)

CN4 ( JQ769237)

3. Withania somnifera; RRL(H)22006

\begin{tabular}{ll} 
WEF1 ( JQ769238 ) & 100 \\
\hline WEF2 ( JQ769239) & 100
\end{tabular}

WEF3 ( JQ769240 ) 100

WEF4 ( JQ769241)

WEF5 ( JQ769242

WEF7 ( JQ769243)

WEF8 ( JQ769244)

WEF9 ( JQ769245 )

WEF10 ( JQ769246)

4. Rauwolfia serpentina; RRL(H)19053

RSL1 ( JQ769247)

coverage $100 \quad 95$

$\begin{array}{ll}100 & 95 \\ 99 & 99\end{array}$

$\begin{array}{ll}98 & 93 \\ 100 & 99\end{array}$

$\begin{array}{ll}100 & 98 \\ 100 & 99\end{array}$

$99 \quad 97$

$100 \quad 99$

$100 \quad 99$

$\begin{array}{ll}100 & 99 \\ 100 & 99\end{array}$

99
99
99

99
93
99
98
99
97
96
99
99
99
99
98
98
99

$100 \quad 98$

$\begin{array}{ll}100 & 99 \\ 100 & 94\end{array}$

$100 \quad 95$

$100 \quad 97$

RSL2 ( JQ769248)

RSL2 ( JQ769248 ) 100

RSL3 ( JQ769249)

RSL4 ( JQ769250)

RSL5 ( JQ769251)

RSS2 ( JQ769252)

RSS3 ( JQ769253)

RSS4 ( JQ769254

RSS5 ( JQ769255)

RSS6 ( JQ769256)

RSS7 ( JQ769257)

RSS9 ( JQ769258)

RSR1 ( JQ769259)

Chaetomium globosum, GQ365152.1

Valsa sordida, HQ420239.1
Thielavia subthermophila, JN390827.1

Thielavia subthermophila, JN390827.1

Alternaria alternata, JN038476.1

Schizophyllum commune, EU030374.1

Alternaria sp. JN689942.1

Alternaria brassicae, JF439450.1

Gibberella moniliformis, GQ168841.1

Cochliobolus lunatus, GQ328851.1

Fusarium sp., EU236709.1

Fusarium equiseti, EU595566.1

Gibberella moniliformis, JF499680.1

Hypoxylon fragiforme, JN564001.1

Nigrospora sphaerica, HQ608030.1

$100 \quad 99$

100
100

$100 \quad 98$

$\begin{array}{ll}100 & 97 \\ 100 & 98 \\ 100 & 97\end{array}$

$100 \quad 98$

$\begin{array}{ll}100 & 99 \\ 100 & 97\end{array}$

$100 \quad 97$

$100 \quad 97$

100

98

Cercophora caudata, AY999135.1

Cladosporium cladosporioides, JN618353.1

Alternaria brassicae, JF439438.1

Alternaria sp. HQ596520.1

Cladosporium cladosporioides, GQ221853.1

Fusarium proliferatum, X94171.1

Alternaria brassicae, JF439444.1

Alternaria alternata, JN618076.1

Diaporthe helianthi, AJ312356.1

Fusarium proliferatum, HQ022511.1

Alternaria sp. , HQ875381.1

Alternaria alternata, JN618076.1 Alternaria sp., GU934499.1

Lasiodiplodia theobromae, GQ502453.1

Lasiodiplodia theobromae, GQ502453 
Table 1 The list of endophytes isolated in this study, their host plants and the summary of BLAST results, showing the coverage of the sequences and sequence similarities with the most closely related organisms (Altschul et al. 1997) (Continued)

\begin{tabular}{|c|c|c|c|c|c|}
\hline \multirow[t]{5}{*}{5.} & \multirow[t]{5}{*}{ Cedrus deodara; RRL(H)1832) } & DEF1 ( JQ769260 ) & 100 & 98 & Sordaria humana, EU918705.1 \\
\hline & & DEF2 ( JQ769261 ) & 100 & 100 & Alternaria alternaria, JN618076.1 \\
\hline & & DEF3 ( JQ769262 ) & 100 & 93 & Talaromyces trachyspermus, AY533702.1 \\
\hline & & DEF4 ( JQ769263 ) & 100 & 99 & Cochliobolus spicifer, JN192387.1 \\
\hline & & DEF5 ( JQ769264 ) & 99 & 98 & Scleroconidioma sphagnicola, FR837912.1 \\
\hline \multirow[t]{4}{*}{6.} & \multirow[t]{4}{*}{ Abies pindrow; RRL(H)21551 } & FEF2 ( JQ769265 ) & 99 & 99 & Daldinia fissa, AM292038.1 \\
\hline & & FEF3 ( JQ769266 ) & 99 & 96 & Penicillium oxalicum, GU078430.1 \\
\hline & & FEF4 ( JQ769267 ) & 99 & 98 & Polyporus arcularius, AF516524.1 \\
\hline & & FEF5 ( JQ769268 ) & 98 & 95 & Apiosordaria otanii, GQ922524 \\
\hline \multirow[t]{5}{*}{7.} & \multirow[t]{5}{*}{ Pinus roxburgii; RRL(H)15011 } & K1 ( JQ769269) & 99 & 99 & Petriella sp. EU315012.1 \\
\hline & & K2 ( JQ769270 ) & 100 & 97 & Bipolaris tetramera, HM195268.1 \\
\hline & & K4 ( JQ769271) & 100 & 94 & Trichophaea abundans EU715596 \\
\hline & & K6 ( JQ769272) & 100 & 95 & Penicillium expansum, FJ770072.1 \\
\hline & & K7 ( JQ769273 ) & 99 & 99 & Ulocladium sp. JF311922.1 \\
\hline \multirow[t]{2}{*}{8.} & \multirow{2}{*}{$\begin{array}{l}\text { Nothapodytes nimmoniana; RRL(H) } \\
20702\end{array}$} & NF1 ( JQ769274 ) & 100 & 98 & Phomopsis sp. FJ441623.1 \\
\hline & & NF2 ( JQ769275 ) & 100 & 93 & Petriella setifera, AY882356.1 \\
\hline \multirow[t]{4}{*}{9.} & \multirow[t]{4}{*}{ Platanus orientalis; RRL(H)19697 } & $\mathrm{CH} 2(\mathrm{JQ769276})$ & 100 & 99 & Fusarium tricinctum, HM776425.1 \\
\hline & & $\mathrm{CH3}(\mathrm{JQ769277})$ & 100 & 100 & Fusarium solani, EU314965.1 \\
\hline & & CH5 ( JQ769278) & 100 & 99 & Fusarium sp., EU589150.1 \\
\hline & & CH6 ( JQ769279 ) & 100 & 100 & Gibberella sp., FJ196601.1 \\
\hline \multirow[t]{11}{*}{10.} & \multirow[t]{11}{*}{ Artemisia annua; $R R L(H) 18128)$} & Art ( JQ769280 ) & 100 & 100 & Fusarium tricinctum, AB369452.1 \\
\hline & & Art1 ( JQ769281) & 100 & 99 & Fusarium flocciferum, GQ505465.1 \\
\hline & & Art2 ( JQ769282 ) & 98 & 98 & Gibberella avenacea, HM036596.1 \\
\hline & & Art3 ( JQ769283 ) & 100 & 99 & Sordaria superba, EU551188.1 \\
\hline & & Art4 ( JQ769284 ) & 100 & 100 & Fusarium redolens, JF311916.1 \\
\hline & & Art5 ( JQ769285 ) & 100 & 99 & Chaetomium sp., HQ914898.1 \\
\hline & & Art6 ( JQ769286 ) & 100 & 100 & Alternaria alternata, GU073112.1 \\
\hline & & Art7 ( JQ769287 ) & 100 & 99 & Alternaria alternata, JN618076.1 \\
\hline & & Art8 ( JQ769288 ) & 100 & 99 & Chaetomium globosum,GQ365152.1 \\
\hline & & Art9 ( JQ769289 ) & 100 & 98 & Alternaria sp., HQ914883.1 \\
\hline & & Art10 ( JQ769290 ) & 100 & 99 & Alternaria brassicae, JF439439.1 \\
\hline
\end{tabular}


Table 1 The list of endophytes isolated in this study, their host plants and the summary of BLAST results, showing the coverage of the sequences and sequence similarities with the most closely related organisms (Altschul et al. 1997) (Continued)

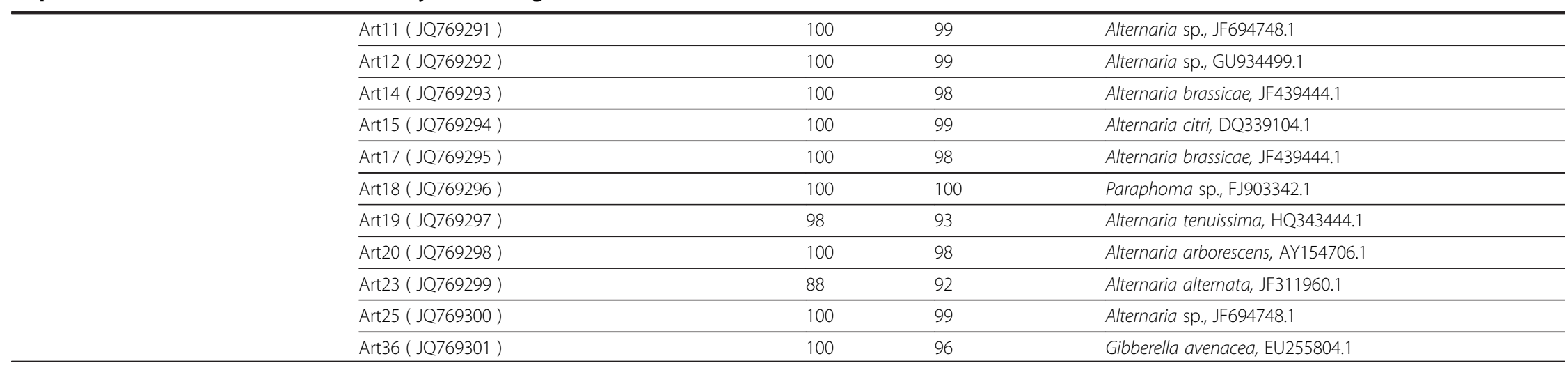


the treatment with alcohol traces of sodium hypochlorite were removed with a rinse in sterile distilled water. The outer tissues were removed after drying the plant tissues under the sterile laminar air flow and passing through the flame. The internal tissues were cut into smaller pieces of 0.5 to $1 \mathrm{~cm}$ and plated on different microbiological media such as water agar, potato dextrose agar and rose bengal agar (Difco). The plates were incubated at $25^{\circ} \mathrm{C}$ for three weeks. Hyphal tips of fungi, emerging out of the plant tissues, were picked and grown on potato dextrose agar in pure culture. After the proper incubation of the plates, seven day old cultures were preserved by placing pieces of hyphal growth in $15 \%$ glycerol and storing at $-70^{\circ} \mathrm{C}$. All the media and chemicals were obtained from Difco (USA). The cultures were also submitted to the IIIM Microbial repository for lyophilization and preservation.

For tentative identification, microscopic slides of each endophyte were prepared by staining with lactophenolcotton-blue (Vainio et al., 1998) and were examined under light microscope (Olympus, USA).

\section{Genomic DNA Extraction}

Each endophytic fungus was cultured in $\mathrm{PD}$ broth at $25^{\circ} \mathrm{C}$ with constant shaking for 7 days. The fungal mycelia were freeze-dried and the genomic DNA was extracted by the CTAB (Cetyl trimethylammonium bromide) method (Ausubel et al. 1994). Briefly, $500 \mathrm{mg}$ of fungal mycelia were vigorously crushed in liquid nitrogen to make a fine powder. The cells were lysed in $10 \mathrm{ml}$ of extraction buffer (50 mM Tris- $\mathrm{HCl}$ pH 8.0, $50 \mathrm{mM}$ EDTA, $0.7 \mathrm{M} \mathrm{NaCl}$, $2 \%$ cetrimide, $1 \%$ SDS and $50 \mu \mathrm{l} \beta$-mercaptoethanol), mixed thoroughly and incubated at $65^{\circ} \mathrm{C}$ for $30 \mathrm{~min}$ with continuous shaking. The lysate was extracted with an equal volume of chloroform/isoamyl alcohol (24:1) and centrifuged at $10,000 \times g$ for $10 \mathrm{~min}$ at $4^{\circ} \mathrm{C}$. The aqueous phase was transferred to a sterile tube; the genomic DNA was precipitated in a $2 \times$ volume of chilled isopropanol and centrifuged at $4^{\circ} \mathrm{C}$ for $10 \mathrm{~min}$ at $10,000 \times g$. The resulting pellet was washed twice with $70 \%$ ethanol, air dried and dissolved in $20 \mu \mathrm{l}$ of sterile Millipore water.

\section{Phylogenetic analyses by partial ITS1-5.8S-ITS2 ribosomal gene sequencing}

Phylogenetic analyses of the endophytes were carried out by the acquisition of the ITS1-5.8S-ITS2 ribosomal gene sequencing. The ITS regions of the fungi were amplified with the universal ITS primers, ITS4 (5/TCC TCCGCTTATTGATATGC3/) and ITS5 (5/GGAAGTA AAAGTCGTAACAA3/), using the polymerase chain reaction (PCR). The PCR conditions used were as follows: initial denaturation at $94^{\circ} \mathrm{C}$ for $3 \mathrm{~min}$ followed by 30 cycles of $94^{\circ} \mathrm{C}$ for $15 \mathrm{sec}, 55^{\circ} \mathrm{C}$ for $30 \mathrm{sec}$., $72^{\circ} \mathrm{C}$ for $45 \mathrm{sec}$., and a final extension at $72^{\circ} \mathrm{C}$ for $7 \mathrm{~min}$. The
$50 \mu \mathrm{l}$ reaction mixture contained $1 \times$ PCR buffer, $200 \mu \mathrm{M}$ each dNTP, $1.5 \mathrm{mM} \mathrm{MgCl}$, 10 pmol. of each primer, 1-5 ng of DNA and 2.0 U of Taq DNA polymerase. The amplified products $(5 \mu \mathrm{l})$ were visualized on $1 \%(\mathrm{w} / \mathrm{v})$ agarose gel to confirm the presence of a single amplified band. The amplicons were purified by Amicon Ultra columns (Millipore, USA) and 20-40 ng were used in a $10 \mu \mathrm{l}$ sequencing reaction using the Big Dye Terminator sequencing kit (v. 3.1). The forward or the reverse primer (2 pmoles) was used in the cycle sequencing reaction. Twenty five cycles of $96^{\circ} \mathrm{C}$ for $10 \mathrm{~s}, 50^{\circ} \mathrm{C}$ for $5 \mathrm{~s}$ and $60^{\circ} \mathrm{C}$ for $4 \mathrm{~min}$ were performed and the extension products were purified by ethanol precipitation, dissolved in $10 \mu \mathrm{l}$ of $\mathrm{HiDi}$ Formamide, incubated at $95^{\circ} \mathrm{C}$ for $5 \mathrm{~min}$ and loaded on ABI Prism 377 Genetic Analyzer (Perkin-Elmer) for sequencing. All the reagents for sequencing were from Applied Biosystems, USA. The amplified products were sequenced and aligned with the sequences in the GenBank by BLASTN program (Altschul et al. 1997) to find out the sequence homology with closely related organisms. Sequences from the closely related organisms were downloaded to construct the phylogenetic trees. Endophytes showing complete sequence homology to each other and belonging to the same plant sample were treated as a single isolate. The ITS1-5.8S-ITS2 sequence for each strain was submitted to the GenBank. Accession numbers of the respective strains are provided in Table 1.

\section{Determination of antimicrobial activities of endophytic extracts}

All endophytic cultures were cultivated at $25^{\circ} \mathrm{C}$ for 15 days in $200 \mathrm{ml}$ of PD broth with constant shaking in an incubator shaker (New Brunswick, USA). The fermentation broth of each endophyte was homogenized with $10 \%$ methanol, extracted thrice with methylene chloride, concentrated and dissolved in DMSO (dimethyl sulphoxide) at a concentration of $10 \mu \mathrm{g} / \mu \mathrm{l}$. The extracts prepared from the endophytes were evaluated for antimicrobial activity against Escherichia coli ATCC 25922 (Gram negative), Staphylococcus aureus ATCC 29978 (Gram positive) and Candida albicans MTCC 4748 (fungal pathogen). Stock solutions of each culture were prepared in Normal Saline Solution $(0.85 \% \mathrm{NaCl}(\mathrm{w} / \mathrm{v}))$ at a concentration of $10^{8}$ cells $/ \mathrm{ml}$. $200 \mu \mathrm{l}$ MuellerHinton Broth (for E. coli and S. aureus) and PD broth (for $C$. albicans) were added to each well in the first column and $100 \mu \mathrm{l}$ of corresponding media were added to the rest of the wells. Extracts of different endophytes were added to the first row at a concentration of $100 \mu \mathrm{g} / \mathrm{ml}$ and serially diluted to make concentrations of $50,25,12.5$ and $6.25 \mu \mathrm{g} / \mathrm{ml}$. Each well was inoculated with $10^{4}$ cells of the relevant test organism and incubated at $37^{\circ} \mathrm{C}$ for $24 \mathrm{~h}$. Each plate had a set of controls: 
a column with broad-spectrum antibiotics (ciprofloxacin and nystatin) as positive controls, a column without the test extract, and one without the relevant test organism. Absorbance was measured spectrophotometrically at $620 \mathrm{~nm}$ and $\mathrm{IC}_{50}$ of the extracts was calculated from the average percent inhibition of three replicates of each concentration (Ellof 1998).

\section{Determination of antimycotic activity of the endophytes}

The endophytes were tested against several plant pathogenic fungi (listed in Table 2) to assess the antifungal potential of their extrolites. Briefly, small plugs (ca. $3 \mathrm{~mm}$ diameter) of each test fungus were placed a centimeter away from the edge of a 7 days old endophytic culture. The plates were wrapped with Parafilm and incubated at $25^{\circ} \mathrm{C}$ for $24-48 \mathrm{~h}$. Inhibition of the test pathogens were reported as \% inhibition as compared to their relevant controls (Ezra et al. 2004).
Determination of Immonomodulatory activity by in vitro lymphocyte proliferation assay

Cell proliferation was measured by MTT assay as described earlier (Mossmann 1983). Splenocytes $\left(2 \times 10^{6}\right.$ cells) were seeded into a 96-well flat-bottom microtiter plate in $100 \mu \mathrm{l}$ complete medium. Variable doses of test extracts $(1 \mu \mathrm{g}$ and $10 \mu \mathrm{g})$, along with Con A $(2.5 \mu \mathrm{g} /$ well) to stimulate T-cell mitogenesis or LPS $(2.5 \mu \mathrm{g} /$ well $)$ to stimulate B-cell mitogenesis, were added making a final volume of $200 \mu \mathrm{l}$. The plates were incubated at $37^{\circ} \mathrm{C}$ with $95 \%$ humidity and $5 \% \mathrm{CO}_{2}$ in a $\mathrm{CO}_{2}$ incubator for $72 \mathrm{hrs} .50 \mu \mathrm{l}$ of MTT solution $(5 \mathrm{mg} / \mathrm{ml})$ was added to each well and the plates were incubated for $4 \mathrm{~h}$. The untransformed MTT was removed after centrifugation at $1400 \times g$ for $5 \mathrm{~min} .200 \mu \mathrm{l}$ of DMSO: $1 \mathrm{~N} \mathrm{HCL}(24: 1)$ was added to each well, and the absorbance was determined in an ELISA reader at $570 \mathrm{~nm}$ after $15 \mathrm{~min}$. All experiments were performed in triplicate and the results were expressed as mean \pm S.D. Student's $t$-test was used

Table 2 Antimycotic activity, represented as the\% growth inhibition, of the endophytes against several plant pathogens

\begin{tabular}{|c|c|c|c|c|c|c|c|c|}
\hline \multirow{2}{*}{$\begin{array}{l}\text { S. } \\
\text { No. }\end{array}$} & \multirow{2}{*}{ Endophyte } & \multicolumn{7}{|c|}{$\%$ Growth inhibition } \\
\hline & & $\begin{array}{l}\text { Fusarium } \\
\text { oxysporum } \\
\text { MTCC } 1755\end{array}$ & $\begin{array}{l}\text { Aspergillus } \\
\text { flavus MTCC } \\
1783\end{array}$ & $\begin{array}{l}\text { Geotrichum } \\
\text { candidum MTCC } \\
3993\end{array}$ & $\begin{array}{l}\text { Verticillium } \\
\text { dahlia MTCC } \\
1351\end{array}$ & $\begin{array}{l}\text { Fusarium } \\
\text { solani MTCC } \\
350\end{array}$ & $\begin{array}{l}\text { Ceratocystis } \\
\text { fimbriata MTCC } \\
2281\end{array}$ & $\begin{array}{l}\text { Rhizoctonia } \\
\text { solani MTCC } \\
4633\end{array}$ \\
\hline 1. & PR4 & $41.3 \pm 2.8$ & $39.0 \pm 1.7$ & $54.0 \pm 3.4$ & $0.0 \pm 0.0$ & $60.0 \pm 0.0$ & $57.3 \pm 2.3$ & $100.0 \pm 0$ \\
\hline 2. & DEF3 & $77 \pm 4.0$ & $65.6 \pm 1.1$ & $51.6 \pm 2.8$ & $52 \pm 3.4$ & $69.4 \pm 0.8$ & $70.9 \pm 3.5$ & $0.0 \pm 0.0$ \\
\hline 3. & DEF4 & $72.6 \pm 2.3$ & $12.6 \pm 2.3$ & $40 \pm 5.1$ & $48.3 \pm 2.8$ & $71.0 \pm 2.0$ & $71.3 \pm 3.2$ & $0.0 \pm 0.0$ \\
\hline 4. & RSL1 & $41.7 \pm 0.0$ & $25.2 \pm 0.5$ & $50.2 \pm 0.9$ & $0.0 \pm 0.0$ & $34.6 \pm 0.3$ & $71.5 \pm 0.0$ & $70.6 \pm 1.2$ \\
\hline 5. & RSR1 & $31.0 \pm 5.1$ & $43.6 \pm 6.0$ & $16.3 \pm 1.1$ & $0.0 \pm 0.0$ & $69 \pm 1.7$ & $100 \pm 0.0$ & $55.3 \pm 2.3$ \\
\hline 6. & WEF1 & $74.8 \pm 1.9$ & $80 \pm 0.0$ & $58.8 \pm 1.0$ & $0.0 \pm 0.0$ & $63.3 \pm 1.5$ & $89.9 \pm 0.8$ & $0.0 \pm 0.0$ \\
\hline 7. & WEF2 & $73.0 \pm 0.0$ & $65.3 \pm 2.8$ & $40.0 \pm 0.0$ & $0.0 \pm 0.0$ & $73.0 \pm 0.0$ & $92.6 \pm 0.5$ & $68.3 \pm 2.8$ \\
\hline 8. & WEF4 & $73.0 \pm 0.0$ & $51.1 \pm 3.4$ & $36.6 \pm 5.7$ & $0.0 \pm 0.0$ & $65.4 \pm 1.5$ & $64.3 \pm 2.3$ & $50.0 \pm 0.0$ \\
\hline 9. & WEF9 & $67.0 \pm 0.0$ & $23.6 \pm 3.3$ & $36.6 \pm 2.7$ & $0.0 \pm 0.0$ & $56.6 \pm 3.5$ & $56 \pm 1.7$ & $31.6 \pm 2.7$ \\
\hline 10 & WEF10 & $60.0 \pm 0.0$ & $31.0 \pm 5.1$ & $20.0 \pm 0.0$ & $0.0 \pm 0.0$ & $54.6 \pm 2.0$ & $51.6 \pm 2.8$ & $37.0 \pm 2.6$ \\
\hline 11 & Art 18 & $73.0 \pm 0.0$ & $51.6 \pm 4.0$ & $40.0 \pm 0.0$ & $0.0 \pm 0.0$ & $63.0 \pm 3.1$ & $56.0 \pm 1.7$ & $46.6 \pm 5.7$ \\
\hline 12 & $\mathrm{~K} 2$ & $50.0 \pm 0.0$ & $31.0 \pm 1.7$ & $19.6 \pm 0.5$ & $0.0 \pm 0.0$ & $59.0 \pm 0.9$ & $70.0 \pm 0.0$ & $65.0 \pm 0.5$ \\
\hline 13 & K4 & $41.7 \pm 0.2$ & $32.5 \pm 1.2$ & $57.0 \pm 0.9$ & $0.0 \pm 0.0$ & $0.0 \pm 0.0$ & $88.6 \pm 0.0$ & $50.0 \pm 1.3$ \\
\hline 14 & $\mathrm{~K} 5$ & $41.7 \pm 0.2$ & $32.5 \pm 1.2$ & $57.0 \pm 0.9$ & $0.0 \pm 0.0$ & $0.0 \pm 0.0$ & $88.6 \pm 0.0$ & $60.0 \pm 1.0$ \\
\hline 15 & K6 & $55.6 \pm 1.1$ & $52.8 \pm 2.2$ & $60.0 \pm 1.8$ & $0.0 \pm 0.0$ & $0.0 \pm 0.0$ & $88.6 \pm 0.0$ & $60.0 \pm 0.7$ \\
\hline 16 & CN1 & $25.0 \pm 0.9$ & $23.1 \pm 0.6$ & $65.1 \pm 1.1$ & $0.0 \pm 0.0$ & $52.0 \pm 1.4$ & $88.6 \pm 0.0$ & $50.0 \pm 0.4$ \\
\hline 17 & $\mathrm{CN} 2$ & $75.0 \pm 2.1$ & $31.0 \pm 1.4$ & $12.0 \pm 0.2$ & $0.0 \pm 0.0$ & $60.0 \pm 1.0$ & $87.0 \pm 0.7$ & $90.0 \pm 3.2$ \\
\hline 18 & Art & $50.0 \pm 1.7$ & $53.8 \pm 0.6$ & $54.3 \pm 0.4$ & $0.0 \pm 0.0$ & $60.0 \pm 0.7$ & $85.7 \pm 0.2$ & $50.2 \pm 1.4$ \\
\hline 19 & Art1 & $50.0 \pm 1.2$ & $30.8 \pm 1.5$ & $50.0 \pm 0.2$ & $0.0 \pm 0.0$ & $46.2 \pm 1.3$ & $71.5 \pm 0.5$ & $53.3 \pm 1.2$ \\
\hline 20 & Art2 & $58.4 \pm 1.7$ & $30.8 \pm 1.3$ & $50.0 \pm 0.7$ & $0.0 \pm 0.0$ & $57.3 \pm 1.2$ & $72.2 \pm 2.8$ & $60.0 \pm 0.9$ \\
\hline 21 & Art4 & $42.0 \pm 1.3$ & $28.6 \pm 0.3$ & $50.0 \pm 0.6$ & $0.0 \pm 0.0$ & $55.1 \pm 0.5$ & $85.7 \pm 1.6$ & $59.4 \pm 0.5$ \\
\hline 22 & Art6 & $50.0 \pm 0.0$ & $38.5 \pm 1.3$ & $65.0 \pm 1.1$ & $0.0 \pm 0.0$ & $30.0 \pm 0.3$ & $88.6 \pm 0.0$ & $65.2 \pm 0.4$ \\
\hline 23 & Art7 & $52.0 \pm 0.3$ & $38.5 \pm 1.3$ & $64.2 \pm 1.3$ & $0.0 \pm 0.0$ & $33.1 \pm 0.5$ & $88.6 \pm 0.0$ & $68.3 \pm 0.7$ \\
\hline 24 & Art9 & $50.0 \pm 2.2$ & $25.0 \pm 1.9$ & $65.3 \pm 2.3$ & $0.0 \pm 0.0$ & $50.0 \pm 0.3$ & $88.6 \pm 0.0$ & $71.0 \pm 0.3$ \\
\hline
\end{tabular}

Data of endophytes possessing significant activity (50\% inhibition or more) against three or more pathogens is presented in this table. 
to analyze statistical significance of the differences between the control and the treated values.

\section{Results}

\section{Phylogenetic affinities of the endophytic fungi}

The acquisition of ITS1-5.8S-ITS2 sequence data and their analyses showed diverse taxonomic affinities among the isolated endophytes. In a total of 72 endophytic strains identified in this study, only two Basodiomycete isolates (CN2 and FEF4) were obtained in comparison to 70 isolates of Ascomycetes (Table 1). The sequence of CN2, isolated from Cannabis sativa, showed $99 \%$ similarity to Schizophyllum commune and that of FEF4, isolated from Abies pindrow displayed a homology of $98 \%$ (99\% sequence coverage) with Polyporus arcularius. On microscopic analyses, both these isolates were found to produce sterile mycelia on PDA. These two genera make a separate clade in the phylogenetic analysis (Figure 1). The genera of ascomycetous fungi belonged to Sordariomycetes $(\mathrm{n}=14)$, Dothidiomycetes $(\mathrm{n}=7)$, Eurotiomycetes $(\mathrm{n}=2)$, Pezizomycetes $(\mathrm{n}=1)$ and Mitosporic ascomycota $(\mathrm{n}=1)$, in the decreasing order of incidence. These isolates comprised of 25 genera with highest abundance of Alternaria spp. (24 isolates) and Fusarium spp. (15 isolates, including Gibberella), respectively. These two genera constituted more than half $(54.2 \%)$ of the strains isolated. The highest number of Alternaria strains (13/22) was isolated from Artemisia annua and Rauwolfia serpentina (7/13). Samples of Platanus orientalis were found to harbor only Fusarium spp. representing 4 different strains. Strangely, strains belonging to other genera could not be obtained from any of the samples of this plant. Artemesia annua also possessed several strains of Fusarium as endophytes $(5 / 22)$ whereas almost half of the endophytes of Withania somnifera (4/9) were also Fusarium spp. Interestingly, the endophytes obtained from the conifers, Cedrus sp., Pinus sp. and Abies sp. presented significant taxonomic variations. These hosts harbored 13 different genera collectively, among a total of 27 obtained from all the ten plant species. Picrorhiza kurroa also harbored four endophytic strains showing homology with four different fungal genera. A total number of ten (13.9\%) isolates showed a sequence similarity of $95 \%$ or less with known organisms in the GenBank. Further, these isolates produced sterile mycelia on agar plates and thus could not be identified to the species or genus levels. Figure 2 shows the phylogenetic positions of Fusarium (a) and Alternaria (b) isolates. These two genera comprised of 10 and 6 species, with 15 and 24 numbers of isolates, respectively. The isolates showed significant variations among their ITS sequences. Isolates of Fusarium make 4 different clusters, two of which form multiple clades. WEF4 (Fusarium equiseti) and $\mathrm{CH} 3$ (Fusarium solani) each make a separate outgroup. Likewise, endophytic isolates of Alternaria make 7 different groups. A group of 12 isolates cluster together showing comparatively low taxonomic variations, whereas two other groups with five and three taxa show considerable sequence divergence. Again, CN1 (Alternaria alternata), Art19 (93\% sequence homology and 98\% sequence coverage with Alternaria tenuissima), Art20 (Alternaria arborescens) and Art 23 (92\% sequence homology and 88\% sequence coverage with Alternaria alternata) make separate outgroups.

\section{Antimicrobial activity of the extracts}

Extracts from 29 endophytes showed an $\mathrm{IC}_{50}$ of less than $100 \mu \mathrm{g} / \mathrm{ml}$ against one or more of the test pathogens (Table 3). A total of seven and eight extracts inhibited E. coli and S. aureus with an $\mathrm{IC}_{50}$ of $50 \mu \mathrm{g} / \mathrm{ml}$ or less, respectively. Extracts from three endophytes, K4 (94\% sequence similarity with Trichophaea abundans from Pinus sp.), PR4 (Diaporthe phaseolorum from Picrorhiza sp.) and Art4 (Fusarium redolens from Artemisia sp.) inhibited $S$. aureus strongly with an $\mathrm{IC}_{50}$ of 18,31 and 25 , respectively. Two extracts, Art8 (Chaetomium globosum from Artemisia sp.) and NF1 (Phomopsis sp. from Nothapodytes sp.) showed an $\mathrm{IC}_{50}$ of around $50 \mu \mathrm{g} / \mathrm{ml}$ against both the bacterial pathogens. In comparison, extracts from only three endophytes, Art (Fusarium tricinctum), Art2 (Gibberella avenacea) and Art9 (Alternaria sp.), all hosted by Artemisia annua, were significantly active against the fungal pathogen, Candida albicans with an $\mathrm{IC}_{50}$ of 50, 15 and $50 \mu \mathrm{g} / \mathrm{ml}$, respectively.

\section{Bioactivity against plant pathogens}

All the endophytes were evaluated for antimycotic activity against a panel of seven important plant pathogens. 24 endophytes inhibited three or more pathogens by $50 \%$ or more (Table 2). 6 isolates (DEF3, WEF1, WEF2, Art, Art2 and Art9) were found highly active inhibiting five of the seven plant pathogens. These organisms belonged to (or were related to) the genera, Talaromyces sp., Giberella sp., Cochliobolus sp., Fusarium sp. and Alternaria sp. Among these were also the isolates, Art, Art2 and Art 9, the only strains active against $C$. albicans.

\section{In vitro lymphocyte proliferation by the extracts}

Significant stimulation or inhibition of lymphocytes in vitro, with dose response relationship, was demonstrated by extracts from 17 endophytes (Table 4). A total of 5 extracts, K1, K7 (Petriella sp. and Ulocladium sp., respectively, from Pinus roxbergii), DEF4 (Cochliobolus spicifer from Cedrus deodara) and Art3 and Art4 (Sordaria superba and Fusarium redolens, respectively, from Artemisia sp.) were found to have immunosuppressive properties. Highest inhibition of T-cell proliferation (44\%) was obtained at $1 \mu \mathrm{g} / \mathrm{ml}$ of the Art3 extract whereas 


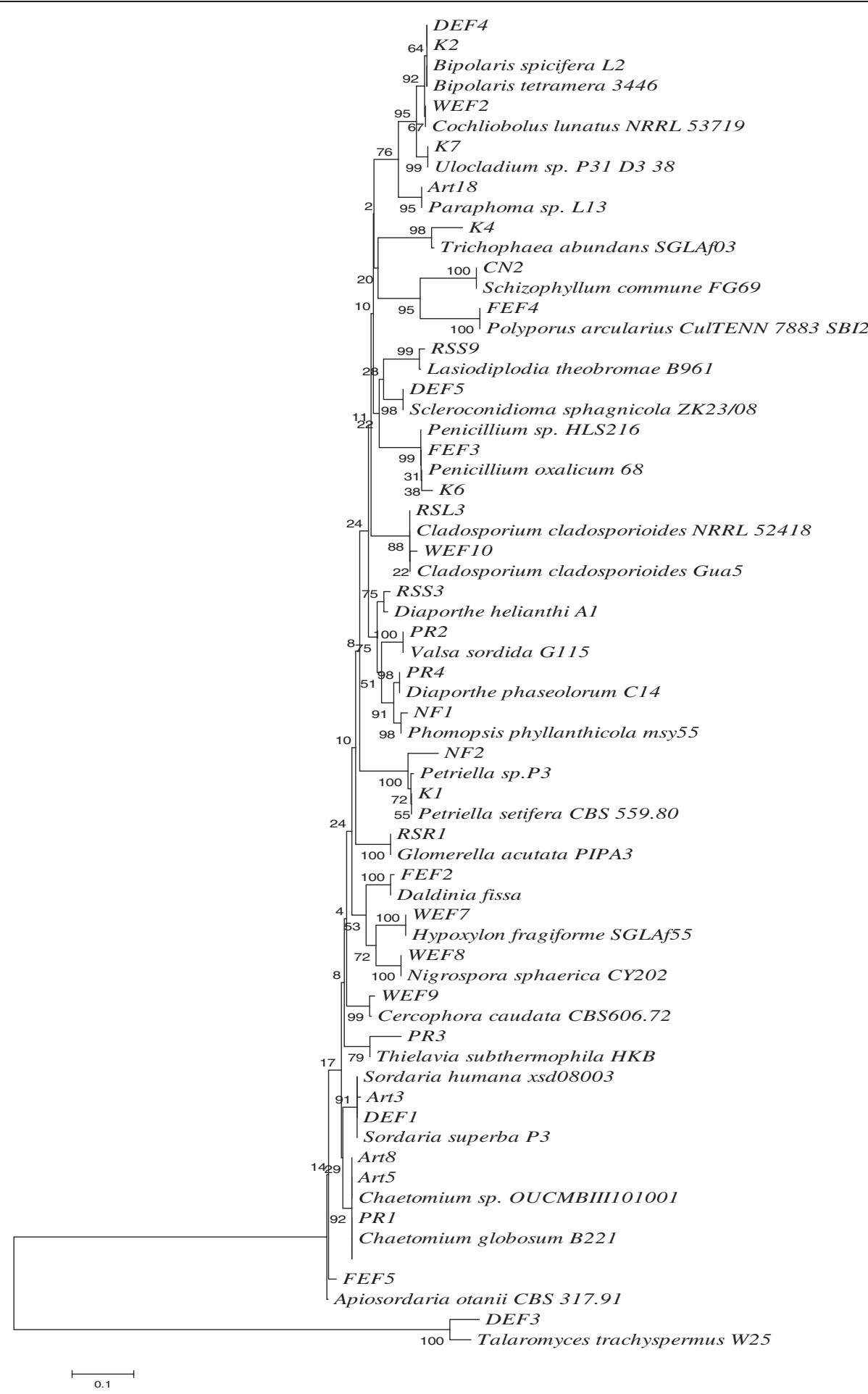

Figure 1 Phylogenetic relationship between different fungal endophytes, isolated in this study, and their close relatives. The evolutionary history was inferred using the Neighbor-Joining method (Saitou and Nei 1987). The optimal tree with the sum of branch length= 2.89592492 is shown. The percentage of replicate trees in which the associated taxa clustered together in the bootstrap test (500 replicates) are shown next to the branches (Felsenstein 1985). The tree is drawn to scale, with branch lengths in the same units as those of the evolutionary distances used to infer the phylogenetic tree. The evolutionary distances were computed using the Maximum Composite Likelihood method (Tamura et al. 2004) and are in the units of the number of base substitutions per site. All positions containing gaps and missing data were eliminated from the dataset (Complete deletion option). There were a total of 192 positions in the final dataset. Phylogenetic analyses were conducted according to Tamura et al. (2007). 


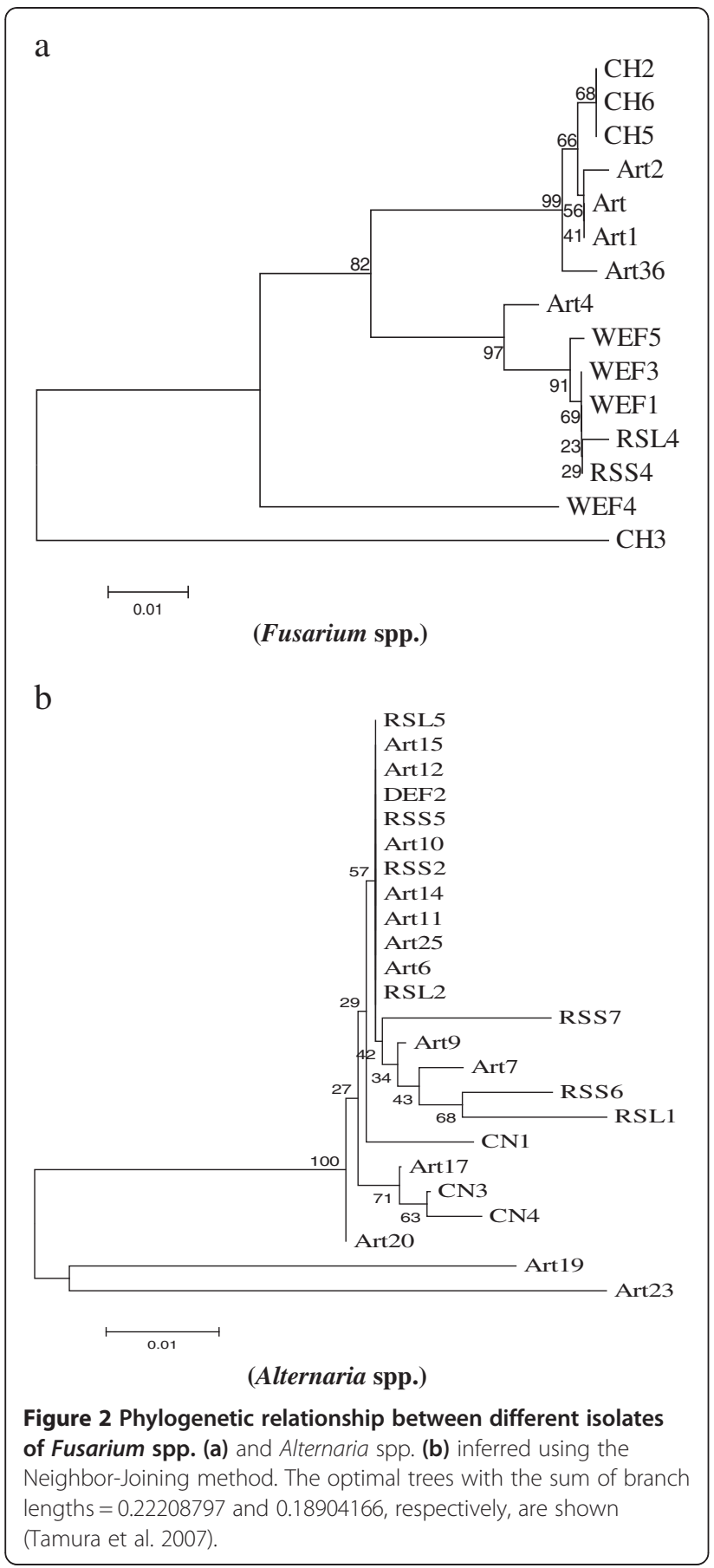

$10 \mu \mathrm{g} / \mathrm{ml}$ of the same extract resulted in comparatively lower inhibition (37\%). However, the extract showed higher inhibition in B-cell proliferation at $10 \mu \mathrm{g} / \mathrm{ml}(52 \%)$ in comparison to that at $1 \mu \mathrm{g} / \mathrm{ml}(38 \%)$. The $\mathrm{K} 1$ extract potentially inhibited B-cell proliferation (54\%) at $1 \mu \mathrm{g} / \mathrm{ml}$ whereas increasing the concentration to $10 \mu \mathrm{g} / \mathrm{ml}$ decreases the activity (22\% inhibition). In contrast to immune suppression, more extracts $(n=11)$ possessed properties that increased proliferation of lymphocytes in a range of $35-58 \%$ when compared with the control.

\section{Discussion}

In this study, endophytic fungi from ten plants growing in the specified Himalayan regions were studied for their phylogenetic affinities and bioactive potential. The plants were selected on the basis of longevity in case of conifers and Platanus sp., and medicinal properties for rest of the plants. The endophytes displayed diverse taxonomic positions and bioactive potential. Endophytes from conifers (Cedrus deodara, Pinus roxbergii and Abies pindrow) possessed a broad range of fungal endophytes, harboring about half of the total genera. These hosts produce bioactive essential oils (Sharma et al. 2008; Kim et al. 2012) that may generate considerable selection pressure for the microbes to colonize inside the plant tissues. They can also survive for several hundred years (Singh and Yadav 2007; Yadav 2009); thus their microbial symbionts may undergo considerable evolutionary changes as the host grows and produces a variety of secondary metabolites during various stages of its life cycle. Diverse endophytes have been isolated by other workers from Abies sp. and Pinus sp. (Yuan et al. 2011; Ganley and Newcombe, 2006). Such host plants, therefore, may represent important ecological niches for novel microbial strains with useful bioactivities.

Alternaria and Fusarium species were the dominant taxa obtained from Withania somnifera, Artemisia annua, Platanus orientalis and Rauwolfia serpentina, as compared to the other host plant. This indicates that endophytic fungi may preferentially colonize plants hosts. However, other factors like soil conditions, climate and the dynamics of soil microflora may also influence the colonization of endophytes in the plant tissues. Although, both of these organisms are fairly explored, they still have the potential to contribute to natural product research as novel bioactive molecules continue to pour in from several of their isolates (Qin et al. 2009; Xu et al. 2010; Mohana et al. 2012). However, it is important to use de-replication techniques to select diverse strains for natural product isolation. One of the most useful information is the inference of phylogenetic relationships based on DNA sequences of ITS regions (Bellemain et al. 2010). Such information is helpful for selection of unique strains based on percent identity and divergence between different strains.

The isolates demonstrating 95\% or lesser sequence homology with the known organisms may be preferentially selected for natural product isolation. In this study, 13.9\% strains represented unknown genera. In a similar study on the endophytes of Abies sp., 27.4\% isolates belonged to unknown species (Yuan et al. 2011). Hence, plant tissues inhabit diverse fungi awaiting characterization and 
Table 3 Antimicrobial activity of DCM (Dichloromethane) extracts of the endophytes against the bacterial strains, $E$. coli ATCC 25922 (Gram negative), S. aureus ATCC 29978 (Gram positive) and C. albicans MTCC 4748 (a fungal pathogen)

\begin{tabular}{|c|c|c|c|c|}
\hline \multirow[t]{2}{*}{ S.No. } & \multirow[t]{2}{*}{ Code } & \multicolumn{3}{|l|}{$\mathrm{IC}_{50}(\mu \mathrm{g} / \mathrm{ml})$} \\
\hline & & $\begin{array}{l}\text { Escherichia coli ATCC } \\
25922\end{array}$ & $\begin{array}{l}\text { Staphylococcus aureus ATCC } \\
29978\end{array}$ & $\begin{array}{l}\text { Candida albicans } \\
\text { MTCC4748 }\end{array}$ \\
\hline 1. & Art & - & - & 50 \\
\hline 2. & Art1 & - & 88 & - \\
\hline 3. & Art 2 & - & - & 15 \\
\hline 4. & Art 4 & - & 30 & - \\
\hline 5. & Art6 & 56 & 92 & - \\
\hline 6. & Art7 & 50 & - & - \\
\hline 7. & Art 8 & 50 & 50 & - \\
\hline 8. & Art9 & - & - & 50 \\
\hline 9. & DEF3 & - & 80 & - \\
\hline 10. & K4 & 95 & 18 & - \\
\hline 11. & K6 & - & 92 & - \\
\hline 12. & K7 & - & 98 & - \\
\hline 13. & FEF2 & 52 & 70 & - \\
\hline 14. & NF1 & 50 & 53 & - \\
\hline 15. & NF2 & 98 & - & - \\
\hline 16. & PR1 & - & 92 & - \\
\hline 17. & PR2 & 90 & - & - \\
\hline 18. & PR3 & 90 & 88 & - \\
\hline 19. & PR4 & 88 & 25 & - \\
\hline 20. & CN1 & 78 & - & - \\
\hline 21. & CN2 & 48 & - & - \\
\hline 22. & CN3 & 88 & - & - \\
\hline 23. & RSL1 & - & 92 & - \\
\hline 24. & RSL2 & - & 75 & - \\
\hline 25. & RSL3 & 80 & 80 & - \\
\hline 26. & RSL4 & 85 & 50 & - \\
\hline 27. & RSL5 & 50 & - & - \\
\hline \multirow[t]{2}{*}{28.} & RSR1 & 80 & 43 & - \\
\hline & Control & 0.10 (Ciprofloxacin) & 0.09 (Ciprofloxacin) & 8.0 (Nystatin) \\
\hline
\end{tabular}

Among all the endophytes included in this study, significant numbers (29 cultures) displayed an $\mathrm{IC}_{50}$ less than $100 \mu \mathrm{g} / \mathrm{ml}$ against one or more of these test organisms.

exploration. Taxonomic novelty may more likely lead to novel chemistry thus facilitating the isolation of new molecules or NCEs.

Extracts from only three fungi, Fusarium tricinctum, Gibberella avenacea and Alternaria sp., all endophytes of Artemisia, displayed considerable antifungal activities against $C$. albicans. These strains also inhibited several phytopathogens significantly. Some strains of Fusarium tricinctum are known to produce different enniatins which have strong biological activities including antifungal properties (Meca et al. 2010). Gibberella avenacea is the teleomorph of Fusarium avenaceum. Strains of the latter have also been found to produce metabolites like enniatins and moniliformin (Booth and Spooner 1984;
Uhlig et al. 2007). It remains to be investigated whether these organisms produce any novel secondary metabolites. Thus, these organisms are being explored for their secondary metabolites. In contrast, several other endophytes were active against only plant pathogenic fungi in co-culture. These organisms need to be studied in detail and may be exploited for disease management for important agricultural crops.

Extracts of five fungi showed significant immune suppression in the in vitro lymphocyte proliferation experiments. It is interesting to know that these fungi, possessing immune suppressing activities, belong to five different genera, thus increasing the chances of obtaining different chemical entities when explored for natural 
Table 4 A summary of in vitro immunomodulatory screening of the endophytic fungal extracts by the lymphocyte proliferation assay

\begin{tabular}{|c|c|c|c|c|}
\hline \multirow[t]{2}{*}{ S.No. } & \multirow{2}{*}{$\begin{array}{l}\text { Test Extract } \\
\text { Cont }\end{array}$} & \multirow[t]{2}{*}{ Dose $\mu \mathrm{g} / \mathrm{ml}$} & \multicolumn{2}{|c|}{ Immunomodulatory activity (\% lymphocyte proliferation) Inhibition $(\downarrow) /$ stimulation $(\uparrow)$} \\
\hline & & & T-Cell & B-Cell \\
\hline & & - & - & - \\
\hline \multirow[t]{2}{*}{1.} & K1 & 1 & $34 \downarrow^{*}$ & $54 \downarrow^{* *}$ \\
\hline & & 10 & $31 \downarrow$ & $22 \downarrow$ \\
\hline \multirow[t]{2}{*}{2.} & K2 & 1 & 15 & $46 \uparrow$ \\
\hline & & 10 & 12 & $49 \uparrow$ \\
\hline \multirow[t]{2}{*}{3.} & K4 & 1 & $31 \uparrow$ & $40 \uparrow$ \\
\hline & & 10 & $42 \uparrow$ & $57 \uparrow$ \\
\hline \multirow[t]{2}{*}{4.} & K7 & 1 & $40 \downarrow^{* *}$ & $37 \downarrow^{*}$ \\
\hline & & 10 & $25 \downarrow$ & $46 \downarrow^{* *}$ \\
\hline \multirow[t]{2}{*}{5.} & DEF3 & 1 & $32 \uparrow$ & $65 \uparrow^{* *}$ \\
\hline & & 10 & $37 \uparrow$ & $48 \uparrow$ \\
\hline \multirow[t]{2}{*}{6.} & DEF4 & 1 & $34 \downarrow$ & $51 \downarrow$ \\
\hline & & 10 & $34 \downarrow$ & $44 \downarrow$ \\
\hline \multirow[t]{2}{*}{7.} & Art & 1 & $28 \uparrow$ & $47 \uparrow$ \\
\hline & & 10 & $33 \uparrow$ & $22 \uparrow$ \\
\hline \multirow[t]{2}{*}{8.} & Art3 & 1 & $44 \downarrow^{*}$ & $38 \downarrow^{*}$ \\
\hline & & 10 & $37 \downarrow^{*}$ & $52 \downarrow^{* *}$ \\
\hline \multirow[t]{2}{*}{9.} & Art4 & 1 & $25 \downarrow$ & $51 \downarrow$ \\
\hline & & 10 & $40 \downarrow^{* *}$ & $45 \downarrow^{* *}$ \\
\hline \multirow[t]{2}{*}{10.} & FEF2 & 1 & $56 \uparrow$ & $40 \uparrow^{*}$ \\
\hline & & 10 & $29 \uparrow$ & $47 \uparrow^{* *}$ \\
\hline \multirow[t]{2}{*}{11.} & FEF4 & 1 & $57 \uparrow^{* *}$ & 11 \\
\hline & & 10 & $62 \uparrow^{* *}$ & 18 \\
\hline \multirow[t]{2}{*}{12.} & NF2 & 1 & $14 \uparrow$ & $32 \uparrow^{*}$ \\
\hline & & 10 & $28 \uparrow$ & $45 \uparrow$ \\
\hline \multirow[t]{2}{*}{13.} & PR1 & 1 & $51 \uparrow^{* * *}$ & $19 \uparrow$ \\
\hline & & 10 & $34 \uparrow$ & $14 \uparrow$ \\
\hline \multirow[t]{2}{*}{14.} & PR2 & 1 & $15 \uparrow$ & $48 \uparrow^{* *}$ \\
\hline & & 10 & $28 \uparrow$ & $34 \uparrow$ \\
\hline \multirow[t]{2}{*}{15.} & PR3 & 1 & $48 \uparrow$ & $43 \uparrow$ \\
\hline & & 10 & $28 \uparrow$ & $54 \uparrow^{* *}$ \\
\hline \multirow[t]{2}{*}{16.} & PR4 & 1 & $25 \uparrow$ & $15 \uparrow$ \\
\hline & & 10 & $16 \uparrow$ & $44 \uparrow^{*}$ \\
\hline \multicolumn{2}{|c|}{ Betamethasone } & 0.005 & $46 \downarrow$ & $34 \downarrow$ \\
\hline \multicolumn{2}{|c|}{ Levamisole } & 0.05 & $29 \uparrow$ & $43 \uparrow$ \\
\hline
\end{tabular}

16 extracts demonstrated significant immune-modulation. Levamisole (as stimulator) and Betamethasone (as an immunesuppressor) were used as positive controls. Data are presented as \% inhibition or stimulation of sets of independent experiments. ${ }^{*} \mathrm{P}<0.05$ and ${ }^{* *} \mathrm{P}<0.01$ represent significant difference compared with cells treated with Levamisole and Betamethasone.

product isolation. Despite the availability of effective immunosuppressive drugs in the market, their inherent toxic effects prompts search for alternative immunosuppressants (Cooper and Wiseman, 2010). Fungi are the preferable sources of such molecules owing to the fungal origin of cyclosporins and the fact that they are highly unexplored (Twentyman 1992; Staley et al. 1997 ). Endophytes from some of the plants explored in this study have been studied earlier with the aim to isolate the host metabolites from the microbial partner (Puri et al. 2007; Rehman et al. 2009). However, our aim is not to limit the endophytes for the exploration of their host metabolites but look into wide applications of their strains including characterization of their novel secondary metabolites.

Endophytes, selected on the basis of bioactivity and phylogenetic novelty, are under investigation for the 
production of useful bioactive compounds (including VOCs and anticancer compounds) and new molecules with substantial success (data not included). The study indicates that several of these plants support wide spectrum of endophytes with significant bioactive potential. Thus, concerted efforts should be carried out for bioprospection in the Western Himalayas to tap and conserve the microbial resources of this important biodiversity hotspot and utilize their potential for human welfare. In addition, the endophytic populations of these plants may be studied in detail with an ecological perspective which may help to understand community structure of their endophytes and warrant isolation of diverse endophytic fungi with useful bioactivities.

\section{Competing interests}

The author(s) declare that they have no competing interests.

\section{Authors' contributions}

$M Q$ and SR designed the study and carried out all the experiments on isolation and phylogenetic analyses of endophytes, and their antimycotic and antimicrobial activities. BAH established the protocols for efficient extract preparation from the endophytes. MQ, SJ and BAH prepared the extracts. SR, SJ and SKL collected the plant samples. SKL authenticated all the plants collected. AK and TS carried out experiments on immunomodulation of extracts. MZA helped in analyzing the data. All the authors contributed in writing the manuscript and approved the final version of the paper. The manuscript was mainly drafted by $M Q$ and SR.

\section{Acknowledgements}

This research was supported by the CSIR-IIIM project MLP-1008. The first author is grateful to the Indian Council of Medical Research, New Delhi, India for her Senior Research Fellowship. We also wish to acknowledge the support of Fairoz I. Nazki, Shabir A. Peer and Nazir A. Bhat for facilitating the collection of the host plants and Mr. Jasbir Singh and Mr. Rajinder Kumar for maintaining the cultures in the IIIM microbial repository.

\section{Author details}

${ }^{1}$ Microbial Biotechnology Division, CSIR-Indian Institute of Integrative Medicine, Canal Road, Jammu 180001, India. ${ }^{2}$ Microbial Natural Product Chemistry Division, CSIR-Indian Institute of Integrative Medicine, Canal Road, Jammu 180001, India. ${ }^{3}$ Pharmacology Division, CSIR-Indian Institute of Integrative Medicine, Canal Road, Jammu 180001, India. ${ }^{4}$ Plant Biotechnology Division, CSIR-Indian Institute of Integrative Medicine, Canal Road, Jammu 180001, India. ${ }^{5}$ Centre for Transgenic Plant Development, Department of Biotechnology, Jamia Hamdard, New Delhi 1 10062, India.

Received: 19 August 2012 Accepted: 4 January 2013

Published: 11 January 2013

\section{References}

Altschul SF, Madden TL, Schaffer AA, Zhang JH, Zhang Z, Miller W, Lipman DJ (1997) Gapped BLAST and PSI-BLAST: a new generation of protein database search programs. Nucleic Acids Res 25:3389-3402

Ausubel FM, Brent R, Kingston RE, Moore DD, Seidman JG, Smith JA, Struhl K (1994) Current Protocols in Molecular Biology. John Wiley \& Sons Inc., New York City, NY

Bellemain E, Carlsen T, Brochmann C, Coissac E, Taberlet P, Kauserud H (2010) ITS as an environmental DNA barcode for fungi: an in silico approach reveals potential PCR biases. BMC Microbiol 10:189-197

Bergmann S, Schuemann J, Scherlach K, Lange CV, Brakhage AA (2007) Genome driven discovery of PKS-NRPS hybrid metabolites from Aspergillus nidulans. Nat Chem Biol 3:213-217

Bok JW, Hoffmeister D, Maggio-Hall LA, Renato M, Glasner JD, Keller NP (2006) Genomic mining for Aspergillus natural products. Chem Biol 13:31-37

Booth C, Spooner BM (1984) Gibberella avenacea, teleomorph of Fusarium avenaceum, from stems of Pteridium aquilinum. T Brit Mycol Soc 82:178-180
Clardy J, Walsh C (2004) Lessons from natural molecules. Nature 432:829-837

Cooper JE, Wiseman AC (2010) Novel immunosuppressive agents in kidney transplantation. Clin Nephrol 73:333-343

Demain AL (1999) Pharmaceutically active secondary metabolites of microorganisms. Appl Microbiol Biotechnol 52:455-463

Ellof JN (1998) A sensitive and quick microplate method to determine the minimal inhibitory concentration of plant extracts for bacteria. Planta Med 64:711-713

Ezra D, Hess WH, Strobel GA (2004) New endophytic isolates of M. albus, a volatile antibiotic-producing fungus. Microbiology 150:4023-4031

Felsenstein J (1985) Confidence limits on phylogenies: An approach using the bootstrap. Evolution 39:783-791

Ganley RJ, Newcombe G (2006) Fungal endophytes in seeds and needles of Pinus monticola. Mycol Res 110:318-327

Hanson T, Brooks TM, Da Fonseca GA, Hoffmann M, Lamoreux JF, Machlis G, Mittermeier CG, Mittermeier RA, Pilgrim JD (2009) Warfare in biodiversity Hotspots. Conserv Biol 23:578-587

Hertweck C (2009) Hidden biosynthetic treasures brought to light. Nat Chem Biol 5:450-452

Heywood VH (ed) (1995) Global biodiversity assessment. Cambridge University Press, Cambridge, UK

Keller NP, Turner G, Bennett JW (2005) Fungal secondary metabolism-from biochemistry to genomics. Nature Rev Microbiol 3:937-947

Khosla C (1997) Harnessing the biosynthetic potential of modular polyketide synthases. Chem Rev 97:2577-2590

Khuroo AA, Rashid I, Reshi Z, Dar GH, Wafai BA (2007) The alien flora of Kashmir Himalaya. Biol Invasions 9:269-292

Kim JH, Lee HJ, Jeong SJ, Lee MH, Kim SH (2012) Essential oil of Pinus koraiensis leaves exerts antihyperlipidemic effects via up-regulation of low-density lipoprotein receptor and inhibition of Acyl-coenzyme A: cholesterol acyltransferase. Phyther Res. doi:10.1002/ptr.3734

Knappe TA, Linne U, Zirah S, Rebuffat S, Xie X, Marahiel MA (2008) Isolation and structural characterization of capistruin, a lasso peptide predicted from the genome sequence of Burkholderia thailandensis E264. J Am Chem Soc 13:11446-11454

Kusari S, Zühlke S, Spiteller M (2009) An endophytic fungus from Camptotheca acuminata that produces camptothecin and analogues. J Nat Prod 72:2-7

McAlpine JB, Bachmann BO, Piraee M, Tremblay S, Alarco AM, Zazopoulos E, Farnet CM (2005) Microbial genomics as a guide to drug discovery, structural elucidation: ECO02301, a novel antifungal agent, as an example. J Nat Prod 68:493-496

Meca G, Soriano JM, Gaspari A, Ritieni A, Moretti A, Mañes J (2010) Antifungal effects of the bioactive compounds enniatins $A, A(1), B, B(1)$. Toxicon 56 (3):480-485

Mohana KP, Zuehlke S, Priti V, Ramesha BT, Shweta S, Ravikanth G, Vasudeva R, Santhoshkumar TR, Spiteller M, Umashaanker R (2012) Fusarium proliferatum, an endophytic fungus from Dysoxylum binectariferum Hook.f, produces rohitukine, a chromane alkaloid possessing anti-cancer activity. Antonie Van Leeuwenhoek 101:323-329

Mossmann T (1983) Rapid colorimetric assay for cellular growth and survival: application to proliferation and cytotoxicity assays. J Immunol Methods 65:55-63

Paul Antony C, Kumaresan D, Hunger S, Drake HL, Murrell J, Shouche YS (2012) Microbiology of Lonar Lake and other soda lakes. ISME J. doi:10.1038/ ismej.2012.137

Porras-Alfaro A, Bayman P (2011) Hidden fungi, emergent properties: endophytes and microbiomes. Annu Rev Phytopathol 49:291-315

Puri SC, Nazir A, Chawla R, Arora R, Riyaz-Ul-Hassan S, Amna T, Ahmad B, Verma V, Singh S, Sagar R, Sharma A, Kumar R, Sharma RK, Qazi GN (2006) The endophytic fungus Trametes hirsuta as a novel alternative source of podophyllotoxin and related aryl tetralin lignans. J Biotechnol 122:494-510

Puri SC, Amna T, Khajuria A, Gupta A, Arora R, Spiteller M, Qazi GN (2007) Immunomodulatory activity of an extract of the novel fungal endophyte Entrophospora infrequens isolated from Nothapodytes foetida (Wight) Sleumer. Acta Microbiol Immunol Hung 54:237-260

Qin JC, Zhang YM, Hu L, Ma YT, Gao JM (2009) Cytotoxic metabolites produced by Alternaria no.28, an endophytic fungus isolated from Ginkgo biloba. Nat Prod Commun 4:1473-1476

Rehman S, Shawl AS, Kour A, Sultan P, Ahmad K, Khajuria R, Qazi GN (2009) Comparative studies and identification of camptothecin produced by an endophyte at shake flask and bioreactor. Nat Prod Res 23:1050-1057 
Riyaz-UI-Hassan S, Strobel GA, Booth E, Knighton B, Floerchinger C, Sears J (2012) Modulation of volatile organic compound formation in the Mycodiesel producing endophyte- Hypoxylon sp. C1-4. Microbiology 158:464-473

Saitou N, Nei M (1987) The neighbor-joining method: A new method for reconstructing phylogenetic trees. Mol Bio Evol 4:406-425

Schroeckh V, Scherlach K, Nützmann HW, Shelest E, Schmidt-Heck W, Schuemann J, Martin K, Hertweck C, Brakhage AA (2009) Intimate bacterial-fungal interaction triggers biosynthesis of archetypal polyketides in Aspergillus nidulans. Proc Natl Acad Sci USA 106:14558-14563

Selvin J, Ninawe AS, Kiran GS, Lipton AP (2010) Sponge-microbial interactions: Ecological implications and bioprospecting avenues. Crit Rev Microbiol 36:82-90

Sharma PR, Shannmugavel M, Saxena AK, Qazi GN (2008) Induction of apoptosis by a synergistic lignan composition from Cedrus deodara in human cancer cells. Phytother Res 22:1587-1594

Sieber SA, Marahiel MA (2005) Molecular mechanisms underlying nonribosomal peptide synthesis: approaches to new antibiotics. Chem Rev 105:715-738

Singh J, Yadav RR (2007) Dendroclimatic potential of millennium-long ring-width chronology of Pinus gerardiana from Himachal Pradesh, India. Curr Sci 93:833-836

Staley JT, Castenholz RW, Colwell RR, Holt JG, Kane MD, Pace NR, Saylers AA, Tiedje JM (1997) The microbial world: foundation of the biosphere. American Academy of Microbiology, Washington DC, p 32

Staniek A, Woerdenbag HJ, Kayser O (2009) Taxomyces andreanae: A presumed paclitaxel producer demystified? Planta Med 75:1561-1566

Stierle A, Strobel GA, Stierle DB (1993) Taxol and taxane production by Taxomyces andreanae, an endophytic fungus of Pacific yew. Science 260:214-216

Strobel G (2006) Harnessing endophytes for industrial microbiology. Curr Opin Microbiol 9:240-244

Strobel GA, Daisy B (2003) Bioprospecting for microbial endophytes and their natural products. Microbiol Mol Biol Rev 67:491-502

Tamura K, Dudley J, Nei M, Kumar S (2007) MEGA4: Molecular Evolutionary Genetics Analysis (MEGA) software version 4.0. Mol Bio Evol 24:1596-1599

Tamura K, Nei M, Kumar S (2004) Prospects for inferring very large phylogenies by using the neighbor-joining method. Proc Natl Acad Sci USA 101:11030-11035

Twentyman PR (1992) Cyclosporins as drug resistance modifiers. Biochem Pharmacol 43:109-117

Uhlig S, Jestoi M, Parikka P (2007) Fusarium avenaceum- the North European situation. Int J Food Microbiol 119:17-24

Vainio EJ, Korhonen K, Hantula J (1998) Genetic variation in Phlebiopsis gigantean as detected with random amplified microsatellite (RAMS) markers. Mycol Res 2:187-192

Wang LW, Zhang YL, Lin FC, Hu YZ, Zhang CL (2011) Natural products with antitumor activity from endophytic fungi. Mini Rev Med Chem 11:1056-1074

Xu L, Wang J, Zhao J, Li P, Shan T, Wang J, Li X, Zhou L (2010) Beauvericin from the endophytic fungus, Fusarium redolens, isolated from Dioscorea zingiberensis and its antibacterial activity. Nat Prod Commun 5:811-814

Yadav RR (2009) Tree ring imprints of long-term changes in climate in Western Himalaya, India. J Biosci 34:700-707

Yuan ZL, Rao LB, Chen YC, Zhang CL, Wu YG (2011) From pattern to process: species and functional diversity in fungal endophytes of Abies beshanzuensis. Fungal Biol 115:197-213

Zhang Y, Han T, Ming Q, Wu L, Rahman K, Qin L (2012) Alkaloids produced by endophytic fungi: a review. Nat Prod Commun 7(7):963-968

doi:10.1186/2193-1801-2-8

Cite this article as: Qadri et al:: Identification and bioactive potential of endophytic fungi isolated from selected plants of the Western Himalayas. SpringerPlus 2013 2:8.

\section{Submit your manuscript to a SpringerOpen ${ }^{\circ}$ journal and benefit from:}

- Convenient online submission

- Rigorous peer review

- Immediate publication on acceptance

- Open access: articles freely available online

- High visibility within the field

- Retaining the copyright to your article

Submit your next manuscript at springeropen.com 